\title{
GEOCONSERVAÇÃO NOS CAMINHOS DA SERRA DO MAR
}

\author{
Fernando Amaro Pessoa ${ }^{(a)}$, Pedro Berruezo Marques ${ }^{(b)}$ \\ (a) CEFET/RJ - campus Petrópolis / Programa de Pós-Graduação em Geografia da UFRJ, E-mail: \\ fap_rj@hotmail.com \\ (b) Graduando em Geografia - IGEO/UFRJ, E-mail: pberruezo.93@gmail.com
}

\section{Eixo: GEODIVERSIDADE, GEOARQUEOLOGIA E PATRIMÔNIO NATURAL}

\begin{abstract}
RESUMO
A Geoconservação, em sentido amplo, tem como objetivo a utilização e gestão sustentável de toda a geodiversidade, englobando todo o tipo de recursos geológicos (BRILHA, 2005). Porém, boa parte da biodiversidade da Serra dos Órgãos é condicionada a sua expressiva geodiversidade, o que de certa forma condicionou todo o seu processo de ocupação e a sóciodiversidade ali presente. Com base nisso cabe pensar em uma "geobiosóciodiversidade" e em estratégias para sua conservação. E é dentro deste contexto que tais propostas podem ser efetivadas com base nos "Caminhos da Serra do Mar", projeto de criação de uma trilha de longa duração que percorre diversos municípios e corta algumas das unidades de conservação do Mosaico da Mata Atlântica Central Fluminense. Além disso, o presente projeto possibilitará uma discussão sobre o papel dos Parques Nacionais e dos Geoparques em propostas de conservação da geobiosóciodiversidade, analisando como as diferentes estratégias podem convergir em prol de um interesse comum.
\end{abstract}

PALAVRAS-CHAVE: Geoconservação; Geobiodiversidade.

\section{Desenvolvimento}

Ao considerar que a região sudeste não se constitui em uma margem passiva como se preconizava a visão clássica na Teoria da Tectônica de Placas (Zalán e Oliveira, 2005), e sim como parte integral do Sistema de Riftes Cenozoicos do Sudeste do Brasil (SRCSB), é possível ressaltar o debate sobre a formação e desenvolvimento de seu embasamento cristalino e o relevo, que diferem em 500 milhões de anos entre sua formação e seu desenvolvimento, tema que pode ter uma divulgação científica importante em roteiros geoturísticos com esse potencial.

Há cerca de $60 \mathrm{Ma}$, o soerguimento de toda a região sudeste foi acompanhado por um vulcanismo alcalino responsável pelo soerguimento e afundamento de diversos blocos que se constituíram em um conjunto de grábens, vales e bacias sedimentares localizados entre horstes, ou seja, as serras. Foram nestes grábens que se acumularam, com o passar do tempo, sedimentos fluviais e lacustres e deram origem às pequenas bacias sedimentares localizadas entre as Serras do Mar e da Mantiqueira (Serra e Serra, 2012). Após a 


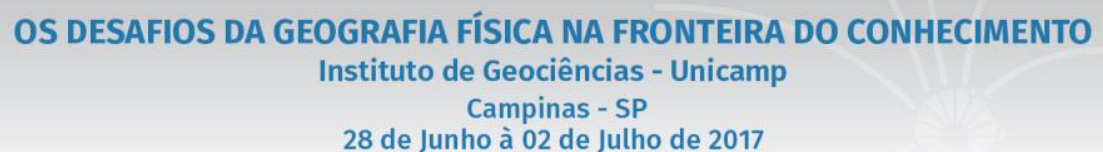

formação dos mesmos, seguiu-se uma nova "calmaria" tectônica onde o intemperismo e a erosão são os principais atores até hoje.

A história natural do Rio de Janeiro e suas perspectivas físicas, ecológicas e socioambientais formam a base para uma compreensão maior de sua importância e, com isso, trabalhar com a Geoconservação da mesma torna-se relevante. De acordo com Sharples (2002),

A Geoconservação tem como objetivo a preservação da diversidade natural (ou geodiversidade) de significativos aspectos e processos geológicos (substrato), geomorfológicos (formas de passagem) e de solo, mantendo a evolução natural (velocidade e intensidade) desses aspectos e processos.

Assim, a Geoconservação, em sentido amplo, tem como objetivo a utilização e gestão sustentável de toda a geodiversidade, englobando todo o tipo de recursos geológicos (BRILHA, 2005). Porém, boa parte da biodiversidade da Serra dos Órgãos é condicionada a sua expressiva geodiversidade, o que de certa forma condicionou todo o seu processo de ocupação e a sóciodiversidade ali presente. Com base nisso cabe pensar em uma "geobiosóciodiversidade" e em estratégias para sua conservação...

E é dentro deste contexto que tais propostas podem ser efetivadas com base nos "Caminhos da Serra do Mar", projeto de criação de uma trilha de longa duração que percorre diversos municípios e corta algumas das unidades de conservação do Mosaico da Mata Atlântica Central Fluminense, composto por quatro trechos: Caminho do Ouro; Cobiçado Ventania; Uricanal e Travessia Petrópolis-Teresópolis (extremamente representativos da diversidade de elementos da geobiosociodiversidade, relevantes na história natural do Rio de Janeiro).

Deste modo, o presente projeto traça algumas propostas visando o enriquecimento da distribuição de suas informações. Assim, os objetivos (ainda em elaboração) que serão desenvolvidos são: organização de um inventário georreferenciado dos elementos da geobiosóciodiversidade dos "Caminhos da Serra do Mar"; elaboração de roteiros geoturísticos; elaboração de "painéis interpretativos" que expliquem a formação da Serra do Mar e da baixada da Guanabara na escala da paisagem; projetos educacionais e de divulgação científica em instituições de ensino formais e não-formais; divulgação de todo o conhecimento e material gerado na internet.

Comumente os projetos de Geoconservação são utilizados como base na elaboração de propostas de Geoparques, os quais representam uma área suficientemente grande e limites bem definidos para servir ao desenvolvimento econômico local. No entanto, um geoparque não é uma unidade de conservação, nem é uma nova categoria de área protegida, em que a ausência de um enquadramento legal de um geoparque é apontada como uma das razões do sucesso dessa iniciativa em nível mundial (CPRM). Em suma, um geoparque, no conceito da Unesco, deve: preservar o patrimônio geológico para futuras gerações 
(geoconservação); educar e ensinar o grande público sobre temas geológicos e ambientais e prover meios de pesquisa para as geociências; assegurar o desenvolvimento sustentável através do geoturismo, reforçando a identificação da população com sua região, promovendo o respeito ao meio ambiente e estimulando a atividade socioeconômica com a criação de empreendimentos locais, pequenos negócios, indústrias de hospedagem e novos empregos; gerar novas fontes de renda para a população local e a atrair capital privado.

Assim, o presente projeto possibilitará uma discussão sobre o papel dos Parques Nacionais e dos Geoparques em propostas de conservação da geobiosóciodiversidade, analisando como as diferentes estratégias podem convergir em prol de um interesse comum.

\section{REFERÊNCIAS}

BRILHA, J. 2005. Patrimônio Geológico e Conservação: A conservação da natureza na sua vertente geológica, pg. 33. Editora Palimage.

SERRA, M.V.; SERRA, Maria Teresa F. - GUIA DE HISTÓRIA NATURAL DO RIO DE JANEIRO. Rio de Janeiro: Cidade Viva. 2012.

ZALÁN, Pedro V.; OLIVEIRA, João A. B. Origem e evolução estutural do Sistema de Riftes Cenozóicos do Sudeste do Brasil. B. Geoci. Petrobras, Rio de Janeiro, v.13, n.2, p. 269-300, maio/nov. 2005.http://www.cprm.gov.br/publique/Gestao-Territorial/Geoparques-134 